\title{
Determination of Urinary Iodine Excretion to Assess Iodine Deficiency Disorder among Pregnant Women in District Hospital of Sindhupalchowk, Nepal
}

\author{
Vivek Kumar Singh ${ }^{1 *}$, Anand Ballabh Joshi ${ }^{1}$, Chitra Kumar Gurung ${ }^{l}$ and Megha Raj \\ Banjara $^{2}$ \\ ${ }^{1}$ Public Health and Infectious Disease Research Center, New Baneshwor, \\ Kathmandu, Nepal \\ ${ }^{2}$ Central Department of Microbiology, TribhuwanUniversity, Kirtipur, Nepal \\ *Corresponding Author \\ viveksingh1424@gmail.com
}

\begin{abstract}
Pregnant women and infants are risk populations of iodine deficiency disorders (IDD). Therefore, this study was designed to explore the status of IDD among pregnant women through the analysis of urinary iodine excretion (UIE). A total of 94 pregnant women from Chautara Hospital Sindhupalchowk were included to analyze UIE through Sandell-Kolthoff Reaction. Although the general clinical status of women was satisfactory, the urinary iodine excretion revealed that still, 18.0 percent of pregnant women in Sindhupalchowk had insufficient iodine intake. This indicates that pregnant women are still at risk of iodine deficiency disorder, and they should be in the priority population for the IDD prevention program.
\end{abstract}

\section{Keywords}

Iodine deficiency disorder, pregnant women, Sindhupalchowk, urine iodine estimation

\section{Introduction}

Iodine is the essential micronutrient required for the health of every individual of all age groups. It is not required in bulk amount, and only 5 grams of iodine meets the need of an individual with 70 years of life-span(Dhaar and Robbani 2008). The critical nutrient required for the synthesis of thyroid hormone, iodine, plays a pivotal role in fetal neural development during gestation (de Escobar et al., 2007). The bulk of iodine in the earth is available in the ocean, and only scanty is present in the soil. Ultraviolet radiation aids in the deposition of iodine in the soil through volatilization from ocean water. The coastal region is rich in iodine content, whereas the content goes on decreasing in the soil far from the coastal region. The continuous leaching of iodine from soil aids to further deterioration of low iodine content in the regions far from the coastal region (Patrick 2008). Mountainous soils hold deficient levels of iodine, so is the locally grown food, and hence the mountainous population is susceptible to iodine deficiency (Dunn 2014).

Iodine being the component of thyroid hormone, sufficient ingestion of iodine is needed for the healthy growth and development of the human body. Low iodine intake can lead to growth impairment (Farebrother 2015). The most significant contributor leading to the global burden of disease and disability is the micronutrient deficiency of which iodine is the most widespread micronutrient deficiencies worldwide (WHO 2009; Andersson 2012).

Iodine deficiency (ID) is the consequence of iodine intake below the minimum requirement (Shawel 2010). Iodine deficiency is the most common cause of endocrinopathy and the preventable cause of mental retardation (Lyn Patrick 2008). According to the World Health Organization (WHO), approximately 37\% (285 
million) of school-age children and nearly 2 billion individuals worldwide have insufficient iodine intake (WHO 2014; de Benoist 2008). Pregnant and lactating women have increased the dietary requirements of iodine. In pregnancy, mild to moderate iodine deficiency can possess an adverse effect on obstetric and neonatal outcomes, whereas severe iodine deficiency can lead to adverse maternal and fetal consequences (Yarrington and Pearce 2011).

The array of developmental and functional anomalies resulting from iodine deficiency is referred to as iodine deficiency disorder (IDD) (WHO 2007; Zimmermann et al., 2008). The consequences of iodine deficiency disorder are most severe during pregnancy and childhood. During pregnancy, IDD can result in stillbirth, spontaneous abortion, congenital abnormalities, cretinism, and irreversible physical disabilities (Dugassa 2013). However, in children, it causes intellectual dysfunction, brain damage, and improper brain development (Mezgebu 2012).

Most of the iodine in the body is excreted through urine. Hence, in a large population, the best way of determining iodine deficiency is to measure iodine content in the urine samples WHO defines iodine deficiency as a median urine iodine concentration less than $50 \mu \mathrm{g} / \mathrm{L}$ in a population (WHO 2001). There are two ways of urine collection for the measurement of iodine in urine samples; 24-hour urine collection and spot urine sample collection. The 24-hour urine collection is considered as the reference standard, which gives a précised estimate of the iodine excretion and, ultimately, iodine intake. Because of difficulties in performing 24-hour collections for the study of a large population, a single spot urine sample is preferred for the study of a large population (Vejbjerg 2009).

Sindhupalchowk is a mountainous area. The soil of the mountainous area contains a deficient level of iodine, and the locally grown crops are deficient of iodine. Women during pregnancy have additional requirements of iodine, and the lack of adequate iodine levels in pregnant women possesses adverse effects on the child. The reduced amount of iodine in the soil of the mountainous area, the elevated need of iodine for the pregnant women and the dangerous consequences of the low iodine level to the child, justify the burning issue for the research on iodine deficiency disorders among pregnant women of Sindhupalchowk. With these motivations, this cross-sectional study was designed to estimate urine iodine among pregnant women in order to implement iodine supplementation in pregnant women.

\section{Materials and Methods}

\section{Research design}

This cross-sectional study was conducted to determine the status of IDD among pregnant mothers in Chautara Hospital Sindhupalchowk from September 2016 to February 2017. Besides, health education on iodized salt and iodine deficiency disorder was provided to women.

\section{Study site}

The site of this study was Chautara Hospital Sindhupalchowk. Sindupalchowk district is situated in the hilly ecological region of Province-3 of Nepal.

\section{Ethical Approval}

Ethical approval was obtained from the Nepal Health Research Council (Ref. No. 980).

\section{Sample size and sampling}

In a cross-sectional study, the proportion of pregnant mothers having UIEs of $<150 \mu \mathrm{g} / \mathrm{L}$ was $28 \%(p=0.28)$ (Agrawal et al., 2013). Using the maximum tolerable error of $9 \%$, the required sample size for a cross-sectional study was 94 . Therefore, we enrolled 94 pregnant mothers seeking antenatal care (ANC) in Chautara Hospital. Urine samples from those women were collected for the determination of urinary iodine excretion.

\section{Physical examination of pregnant women}

Women visiting Chautara District Hospital for antenatal checkups were examined for blood pressure and general clinical status. The attending nurse/ANM measured the blood pressure of mothers, whereas the medical doctors examined the clinical status of women. 


\section{Collection of urine samples}

Urine samples were collected from 94 pregnant women in the hospital for the analysis of UIE to screen IDD status. The urine samples were collected in a clean, leak-proof container. The collected urine samples were kept in the refrigerator at $-20^{\circ} \mathrm{C}$ until analysis. The UIE analysis was conducted at BP Koirala Institute of Health Sciences (BPKIHS), Dharan.

\section{Urine Iodine Estimation through Ammonium Persulfate Digestion with Spectrophotometric Detection of the Sandell-Kolthoff reaction}

The urine and QC specimenswere allowed to reach the ambient temperature. The sample was vortexed well before akinkg an aliquot for analysis such that no particulates remain on the bottom of the tube. Two hundred fifty $\mu$ l of eachurine samples, working standards, and bench QC were pipetted into a $13 \times 100-\mathrm{mm}$ test tube. All samples were pipetted in duplicate. One $\mathrm{mL}$ of ammonium persulfate solution was added to each tube. All the tubes were mixed and heated on a heating block for 60 minutes at $91^{\circ}-95^{\circ} \mathrm{C}$ (digestion step).

After digestion, the tubes were cooled to room temperature. Arsenious acid solution $(3.5 \mathrm{~mL})$ was added mixed and left to stand for 15 minutes. Ceric ammonium sulfate solution $(400 \mu \mathrm{L})$ was added to each tube and quickly vortexed to mix (A timer was used to keep a constant interval of 30 seconds between additions to successive tubes).

Exactly 30 minutes after the addition of cericammonium sulfate to the first tube, the absorbance was noted at $420 \mathrm{~nm}$ in a spectrophotometer. The successive tubes were read at the same time intervals as when adding the ceric ammonium sulfate.

\section{Data management and analysis}

Collected data were entered into SPSS version 21 and analyzed. Descriptive analyses, as well as qualitative data, were presented. The following classification of urinary iodine excretion (UIE) for pregnant women was used (Table 1).

\section{Results}

\section{Characteristics of women involved in the study}

The age range of women included for UIE was 1842 years. The mean age of the women was 24.07 years (SD-4.90 years). The majority of women (75.5 percent) were age 21-35 years (Table 2).

All of the mothers included in the study had normal blood pressure and normal general clinical status in general health checkup examination (Table not given).

Table 1. WHO classification of iodine deficiency disorders (IDD) based on urinary iodine excretion for pregnant women

\begin{tabular}{lll}
\hline Median Urinary Iodine $(\boldsymbol{\mu g} / \mathbf{L})$ & Iodine intake & Iodine status \\
\hline$<150 \mu \mathrm{g} / \mathrm{L}$ & Insufficient & Severe iodine deficiency \\
$150-249 \mu \mathrm{g} / \mathrm{L}$ & Adequate & Adequate iodine nutrition \\
$250-499 \mu \mathrm{g} / \mathrm{L}$ & Above requirements & Risk of iodine-induced hyperthyroidism \\
$\geq 500 \mu \mathrm{g} / \mathrm{L}$ & Excessive & Risk of adverse health consequences \\
\hline
\end{tabular}

Table 2. Characteristics of the women

\begin{tabular}{lll}
\hline Characteristics & Number $(\mathbf{n = 9 4})$ & Percent \\
\hline Age distribution (in years) & & \\
$<$ or equal to 20 & 21 & 22.3 \\
$21-35$ & 71 & 75.5 \\
More than 35 & 2 & 2.1 \\
Mean age (S.D.) & $23.97 \pm 4.90($ Min.-18; Max.-42) \\
Mean weight $(\mathrm{Kg})$ & Mean weight $(\mathrm{Kg})$ 54.04 \pm 7.37 (Min.-30; Max.-73) & \\
\hline
\end{tabular}


Table 3. Urinary iodine excretion level and iodine intake status

\begin{tabular}{lll}
\hline UIE level $(\boldsymbol{\mu g} / \mathbf{l})$ & Number $(\mathbf{n}=\mathbf{8 9})$ & Percent \\
\hline Insufficient $(<150)$ & 16 & 18.0 \\
Adequate $(150-249)$ & 27 & 30.3 \\
Above requirements $(250-499)$ & 46 & 51.7 \\
Excessive $(\geq 500)$ & 0 & 0.0 \\
\hline
\end{tabular}

Urinary iodine level among pregnant women

Urinary iodine excretion level indicates that 18.0 percent of women had insufficient iodine intake. Similarly, 51.7 percent of women had UIE above the requirement, which was higher than $250 \mu \mathrm{g} / \mathrm{L}$; they are at risk of iodine-induced hyperthyroidism (Table 3).

\section{Discussion}

All the pregnant women attending regular health checkups at the district hospital of Sindhupalchowk were included in this study. The mean age of the pregnant women in this study was $23.97 \pm 4.90$ years, which was similar to the study of Chaudhary et al., (24.45 \pm 4.4years) (2017)and Agrawal et al., (23.73 \pm 3.8 years) (2013).

The blood pressure and clinical status of all the women under study were normal. The urine iodine level was insufficient, that is, below $150 \mu \mathrm{g} / \mathrm{L}$ in eighteen percent of the study population which was similar with the study of Chaudhary et al., (18.48\%) (2017) but reasonably low in comparison with the study of Agrawal et al., (28.88\%) (2013)and Joshi et al., (28.6\%) (2016). In $30.3 \%$ of pregnant women, the urine iodine level was adequate $(150-249 \mu \mathrm{g} / \mathrm{L})$. A similar finding was observed in the study of Joshi et al., (31.6\%) (2016) where as, Agrawal et al., (2013) reported $37.78 \%$ while Chaudhary et al., (2017) reported $23.91 \%$. The urine iodine level was above than required $(250-499 \mu \mathrm{g} / \mathrm{l})$ in $51.7 \%$ which was much higher than that reported by Joshi et al., (34.7\%) (2016)and Agrawal et al., (33.33\%) (2013), however, a little low than the study of Chaudhary et al., (57.61\%) (2017). Excessive urine iodine level (above $500 \mu \mathrm{g} / \mathrm{L}$ ) was not found in any women, whereas Joshi et al., (2016) reported excessive iodine levels in 5.1\% pregnant women.

\section{Conclusions}

Although the general clinical status of women was satisfactory, the urinary iodine excretion revealed that still, $18.0 \%$ of pregnant women in Sindhupalchowk had insufficient iodine intake. This indicates that pregnant women are still at risk of iodine deficiency disorder, and they should be in the priority population for the IDD prevention program.

\section{Acknowledgment}

We would like to thank Mr. Krishna Raj Pant for managerial support and Mr. Chikayoshi Atsuta for financial support. Society financially supported the research for Eliminating Nepalese Iodine Deficiency Disorder (SENID), Osaka, Japan

\section{References}

Agrawal, K., B. H. Paudel, P. N. Singh, S. Majhi, and H. P. Pokhrel. 2013. Urinary Iodine Excretion in Pregnancy: A Pilot Study in the Region of Nepal. Journal of Clinical and Diagnostic Research 7(7);1319-1321.

Andersson, M., V. Karumbunathan, and M. B. Zimmermann. 2012. Global status in 2011 and trends over the past decade. J Nutr 142:744750 .

Chaudhary,L., S. Khatiwada, B. Gelal, S. Gautam, M. Lamsal, H. Pokharel, and N. Baral. 2017. Iodine and Thyroid Function Status, and anti-thyroid Peroxidase Antibody among Pregnant Women in Eastern Nepal. J Nepal Health Res Counc 15(36); 114-119.

Dhaar, G.M., and I. Rabbani. 2008. Nutritional problems of mothers and children. Foundations of Community Medicine. India: Reed Elsevier 2:272-280.

de Benoist, B., E. McLean, M. Andersson, and L. Rogers. 2008.Iodine deficiency in 2007:global progress since 2003. Food Nutr Bull 29(3):195-202.

de Escobar, G.M., M.J. Obregon, and F.E. Del Rey. 2007. Iodine deficiency and brain development in 
the first half of pregnancy.Public Health Nutrition 10(12):1554-1570.

Dugassa, B.2013.Iodine deficiency and women's health: Colonialism's malign effect on health in the Oromia region in Ethiopia. Tor Public Health 5:958-972.

Dunn, J. T., 2014. Iodined efficiency disorders. Up To Date(http://www.uptodate.com/contents/ iodine-deficiency disorders, accessed 26 November 2014).

Farebrother, J., C. E.Naude, L. Nicol, Z.Sang, Z. Yang, M. Andersson, P. L. Jooste, and. B. Zimmermann. 2015. A systematic review of the effects of iodized salt and iodine supplements on prenatal and postnatal growth: study protocol.BMJ Open 5:1-7.

Joshi, A., A. Joshi, S. Bhattarai, M. R. Banjara, C. Atsuta, A. B. Joshi, S. B., Bastola, C. K. Gurung, and. Joshi. 2016. Prevalence and Risk Factors of Iodine Deficiency Disorder (Idd) Among Pregnant Women in District Hospital of Sindhupalchowk, Nepal. Nepal Med Coll J 18(1-2);9-11.

Lyn Patrick, N. D. 2008.I odine: Deficiency and Therapeutic Considerations. Alternative Medicine Review 13(2):116-127.

Mezgebu, Z., A. Mossie, P. Rajesh, G. Beyene. 2012. Prevalence and severity of iodine deficiency disorder among children 6-12 years of age in Shebe Senbo district, Jimma zone, southwest Ethiopia. Ethiop J Health Sci 22:196-204.

Patrick, L., 2008. Iodine: Deficiency and therapeutic considerations. Altern Med Rev 13:116-127.

Shawel, D., S. Hagos, K. Lachat, E. Kimanya, and P. Kolsteren. 2010. Post-production Losses in iodine concentration of salt hamper the control of iodine deficiency disorders: a case study in Northern Ethiopia. J Health PopulNutr 28:238-244.
Vejbjerg, P., N. Knudsen, H. Perrild, P. Laurberg, S. Andersen, L. B. Rasmussen, L. Ovesen, and T, Jørgensen. 2009. Estimation of iodine intake from various urinary iodine measurements in population studies. Thyroid 19(11);1281-1286.

WHO. 2001. World Health Organization (WHO) ICCIDD, UNICEF, WHO. 2. ICCIDD, UNICEF, WHO: 2001. Assessment of iodine deficiency disorders and monitoring their elimination: A guide for program managers. http:/www.who. $\mathrm{int} /$ nutrition/publications/micronutrients/iodine deficiency/9789241595827/en/.

WHO. 2007. World Health Organization, United Nations Children's Fund, International Council for Control of Iodine Deficiency Disorders. Assessment of Iodine deficiency disorders and monitoring their elimination.A guide for program managers. $3^{\text {rd }}$ edn.Geneva, Switzerland: World Health Organization, 2007. http://apps.who.int/ iris/bitstream/10665/43781/1/9789241595827_ eng.pdf.

WHO. 2009. Global health risks: mortality and burden of disease attributable to selected significant risks. Geneva, Switzerland: World Health Organization. http://www.who.int/healthinfo/global_burden disease/GlobalHealthRisks_report_full.pdf

WHO. 2014. Iodine status worldwide. WHO global database on iodine deficiency.Geneva: World Health Organization; 2004 (http://whqlibdoc.who. int/publications/2004/9241592001.pdf? q=iodinestatus-worldwide, accessed 23 October 2014).

Yarrington, C, and E. N. Pearce. 2011. Iodine and Pregnancy. J Thyroid Res 2011;1-8.

Zimmermann, M. B., P. L. Jooste, and C. V. Pande. 2008. Iodine-deficiency disorders. Lancet 372:12511262.30 